\title{
Bazı Domates Çeşitlerinin Milas (Muğla) Tarla Koşullarında Tuta absoluta'nın Ergin Öncesi Popülasyon Yoğunluklarına Etkileri ${ }^{1}$
}

\author{
Yaşar Mutlu TÜRKMEN²*, Cengiz KAZAK ${ }^{3}$
}

\begin{abstract}
ÖZ
Bu çalışmada, Milas (Muğla)'da tarla koşullarında yetiştiriciliği yapılan Solanum lycopersicum L. cv. 5656 (VO-506), BT-236, BT-Tokat $\mathrm{F}_{1}$ çeşitleri ile geleneksel Pembe domates çeşidinin Domates yaprak galeri güvesi Tuta absoluta (Meyrick)'nın ergin öncesi dönemlerinin popülasyon yoğunluklarına etkileri araştırılmıştır. T. absoluta bulaşıklı oranları 2014 yılı üretim sezonunda bildirilen çeşit sırasına göre \%17.62, 19.21, 23.02 ve 13.18 olarak gerçekleşmiştir. Bu değerler 2015 yllı üretim sezonunda ise aynı çeşit sırasına bağlı olarak \%6.39, 4.28, 7.39 ve 4.28 olmuştur. Çalışmada kullanılan domates çeşitlerinde belirlenen vuruk meyve oranları 2014 yılı üretim sezonu için Pembe, BT-Tokat, 5656 ve BT-236 çeşitlerinde sırasıyla \%14.52, 22.65, 25.40 ve 31.99; 2015 yılı üretim sezonunda ise $\% 5.30$, $16.83,10.24$ ve 16.67 olarak saptanmıştır. Her iki yıl için de tüm sonuçlar bir arada değerlendirildiğinde T. absoluta'ya karşın en dayanıklı çeşit Pembe olurken bunu 2014 yılı üretim sezonunda 5656, BT-236, BT-Tokat; 2015 yılı üretim sezonunda ise BT-236, 5656, BT-Tokat çeşitleri izlemiştir.
\end{abstract}

Anahtar kelimeler: Tuta absoluta, popülasyon, Domates çeşitleri, Muğla.

\section{Effects of Some Tomato Cultivars on Population Densities of Immature Stages of Tuta absoluta in Milas (Muğla) Field Conditions}

\begin{abstract}
In this study, the effects of field grown Solanum lycopersicum L. cvs. 5656 (VO-506), BT-236, BTTokat $F_{1}$ and local tomato cv. Pembe were investigated on population densities of Tomato leaf gall moth Tuta absoluta (Meyrick) immature stages in Milas (Muğla). T. absoluta infection rates were determined to be 17.62, 19.21, 23.02 and 13.18\%, based on the cv. order given above during the 2014 tomato-growing season. During the 2015 growing season, these values were 6.39, 4.28, 7.39 and $4.28 \%$, depending on the same order of cvs. The damaged fruit ratios for the cvs. used in the study were 14.52, 22.65, 25.40 and 31.99\% for Pembe, BT-Tokat, 5656 and BT-236 in 2014, and 5.30, $16.83,10.24$ and $16.67 \%$ in 2015 growing seasons, respectively. When all the results for both years were evaluated together, Pink was the most tolerant cv. against $T$. absoluta which was followed by 5656, BT-236 and BT-Tokat in 2014 and BT-236, 5656 and BT-Tokat cvs. in 2015 growing season.

Key words: Tuta absoluta, population, tomato cultivars, Muğla.
\end{abstract}

ORCID ID (Yazar sirasına göre)

0000-0001-6683-9392, 0000-0002-2810-0244

\footnotetext{
${ }^{1} \mathrm{Bu}$ makale birinci yazarın Doktora tez çalışmasının bir bölümü olup, “Çukurova Üniversitesi, Bilimsel Araştırma Projeleri Birimi” tarafından desteklenmiştir (FDK-2014-3036)

${ }^{2}$ Muğla İl Tarım ve Orman Müdürlüğü, Bitkisel Üret. ve Bitki Sağ. Şb. Müd., 48100, Menteşe/MUĞLA

${ }^{3}$ Çukurova Üniversitesi, Ziraat Fakültesi, Bitki Koruma Bölümü, 01330, Sarıçam/ADANA

*E-posta: y.mutluturkmen@gmail.com
} 


\section{Bazı Domates Çeşitlerinin Milas (Muğla) Tarla Koşullarında Tuta absoluta'nın Ergin Öncesi Popülasyon Yoğunluğuna Etkileri}

\section{Giriș}

Yeni dünya kökenli ve Solanaceae familyasına bağlı bir bitki türü olan domates (Solanum lycopersicum L.), son 400 yılda tüm dünyaya yayılmış ve patatesten sonra en fazla üretilen sebze konumuna geçmiştir (ANONIM, 2011; Mamay ve Yanık, 2012; Abak, 2016). Domates yaprak galeri güvesi Tuta absoluta (Meyrick) (Lepidoptera:Gelechiidae), görüldüğü ülkelerde domates üretimini sinırlayan en önemli etmenler arasında olup; domates bitkisinin en önemli lepidopter zararlısıdır. $T$. absoluta Avrupa'da ilk olarak 2006 y1lında İspanya'da saptanmış ve kısa sürede diğer Akdeniz ülkelerine yayılmıştır (Urbaneja ve ark., 2007; EPPO, 2009). Türkiye'de ise ilk olarak 2009 y1lında İzmir' de görülmüş olup; kısa sürede Ege ve Akdeniz kıyı şeridinde bulunan diğer domates üretim alanlarına yayılarak zarar oluşturmaya başlamıştır (Kılıç, 2010; Karut ve ark., 2011; Kasap ve ark., 2011). Dünya'da ve Türkiye'de $T$. absoluta ile mücadelede kullanılan en yaygın yöntemlerden biri kimyasal savaştır (Dos Santos ve ark., 2011; Mahmoud ve ark., 2014; Manavoğlu ve ark., 2019;). Ancak; zararlının insektisitlere karşı direnç geliştirmesi ve yoğun tarım ilacı kullanımından kaynaklanan diğer tüketici ve çevre sorunlarından dolayı kimyasal savaşa alternatif olabilecek diğer sürdürülebilir yöntemlerin kullanılması zorunlu hale gelmiştir. Kimyasal savaşa alternatif olarak kullanılabilecek bu yöntemlerden bir tanesi de kültürel önlemler içerisinde yer alan tolerant veya dayanıklı bitki çeşitlerinin hedef zararlıya karşı mücadele programları içinde kullanılmasıdır (Oliveira ve ark., 2012). Kültür bitkileri zararlılara karşı tercih olunmama, tolerans ve

\section{Materyal ve Yöntem}

\section{Tarla koşullarında farklı domates çeşitlerinde Tuta absoluta'nın ergin öncesi popülasyon gelişmesi}

Denemeler 2014 ve 2015 yıllarında yazlık domates üretim sezonunda tarla koşullarında Çamköy (Milas, Muğla)'de gerçekleştirilmiştir. Çalışmada bölgede yaygın olarak üretimi yapılan Solanum antibiosis yolu ile etkili olmakta olup; çalışmalar $T$. absoluta'nın zarar oranının domates çeşitlerine göre farklılık gösterdiğini ortaya koymuştur (Ecole ve ark., 2001; Silva ve ark., 2015; Rostami ve ark., 2017). T. absoluta'nın ergin öncesi gelişme süresinin yabani domates çeşitleri üzerinde kültür formlarına göre daha uzun, ölüm oranlarının ise daha yüksek olduğu bildirilmiştir (Leite ve ark. 2001). Bir diğer çalışmada ise domates bitkisinin tricosane içeriğinin T. absoluta'nın yaprakta galeri oluşturmasını olumsuz, tetracozan ve hexacozane içeriğinin ise olumlu etkilediği saptanmıştır (Oliveira ve ark., 2009). Bildirilen konukçu bitki özellikleri dışında Oliveira ve ark. (2012), trikom sayısı ve tridecanone içeriği yüksek olan domates çeşitlerinin T. absoluta'ya daha tolerant olduğunu bildirmişlerdir. Benzer şekilde trikom yönünden zengin çeşitlerin $T$. absoluta'nın beslenme, gelişme ve çoğalmasında yavaşlatma etkisi göstermesi nedeniyle zararlı tarafından tercih edilmediği saptanmıştır (Sohrabi ve ark., 2016; Aslan ve ark, 2017; Sridhar ve ark., 2019). Muğla ilinde tarla domatesi yetiştiriciliğinde karşılaşılan en önemli zararlllardan biri de benzer şekilde $T$. absoluta olup; zararlı ile mücadelede en yaygın kullanılan yöntem kimyasal savaştır. Gerçekleştirilen ön çalışmalarda bölgede yerel olarak üreticiliği yapılan Pembe domates çeşidinin diğer ticari domates çeşitlerine göre zararlıya karşı daha tolerant olduğu dikkat çekmiştir. Yukarıda bildirilen tüm gerekçelere bağl1 olarak bu çalışmada bölgede yoğun olarak üretimi yapılan ticari çeşitlerin tarla koşullarında yerel çeşit ile karşılaştırmalı olarak T. absoluta popülasyon gelişmesi ile zararına ilişkin etkilerinin ortaya çıkarılması hedeflenmiştir.

lycopersicum cv. L. 5656, BT-236, BT-Tokat $\mathrm{F}_{1}$ çeşitleri ile geleneksel Pembe domates çeşidi kullanılmıştır (Çizelge 1). Denemelerde dört domates çeşidi üzerinde T. absoluta'nın ergin öncesi dönemlerinin bulaşıklık oranı ile vuruk meyve oranına olan etkileri araştırılmıştır. Denemeler tesadüf blokları deneme desenine göre 3 tekrarlı olarak 


\section{Bazı Domates Çeşitlerinin Milas (Muğla) Tarla Koşullarında Tuta absoluta'nın Ergin Öncesi Popülasyon Yoğunluğuna Etkileri}

gerçekleştirilmiştir. Çalışmalarda kullanılan domates fideleri 2014 ve 2015 yillarında yaz domates üretim sezonu içinde sirasıyla 15 Nisan ve 5 Mayıs tarihlerinde sira üzeri 50, sıra arası ise $100 \mathrm{~cm}$ olacak şekilde dikilmiştir. Parsel ve bloklar arasında meydana gelebilecek etkileşimi en aza indirmek amacıyla aralarında $2 \mathrm{~m}$ güvenlik şeridi bırakılmıştır. 2014 yılı üretim sezonunda her bir parsel büyüklüğü $30 \mathrm{~m}^{2}$ ve parseldeki bitki sayıs1 ortalama 60 adet, 2015 y1lı üretim sezonunda ise parsel büyüklükleri $80 \mathrm{~m}^{2}$ ve her bir parseldeki bitki sayıs1 ortalama 100 adet olarak belirlenmiştir. Çalışmada kullanılan domates çeşitlerine ilişkin özellikler Çizelge 1'de verilmiştir.

Çizelge 1. Çamköy (Milas, Muğla)'de tarla koşullarında Tuta absoluta'nın ergin öncesi dönemlerine etkilerinin belirlenmesinde kullanılan domates çeşitleri

\begin{tabular}{|c|c|c|c|}
\hline Çeşitler & Hasat süresi & Meyve özelliği & $\begin{array}{c}\text { Ortalama meyve ă̆ırlığı } \\
\text { (gr) }\end{array}$ \\
\hline BT-236 & $\begin{array}{c}\text { Orta erkenci } \\
(80-85 \text { gün })\end{array}$ & Sert & $200-250$ \\
\hline BT-Tokat & $\begin{array}{l}\text { Orta erkenci } \\
(75-80 \text { gün })\end{array}$ & Sert & $150-170$ \\
\hline $\mathbf{5 6 5 6}$ & $\begin{array}{l}\text { Orta erkenci } \\
(80-85 \text { gün })\end{array}$ & Sert & $140-180$ \\
\hline Pembe & $\begin{array}{c}\text { Geç } \\
\text { (Yerel çeşit) }\end{array}$ & Yumuşak, ince kabuk & $170-180$ \\
\hline
\end{tabular}

Fidelerin dikim işlemi sonrası bitki vejetatif gelişimi ile birlikte $T$. absoluta'nın yumurta ve larva popülasyon yoğunluğunu belirlemek amacıyla; her parselde 3 farklı noktada ardışık 5 bitkiden; 2014 y1lında 15; 2015 yılında ise 50 'şer adet yaprak örneği tesadüfi olarak alınarak paketlenmiş ve laboratuvara getirilmiştir. Daha sonra yapraklar binoküler

Farklı domates çeşitlerinde Tuta absoluta bulaşıklık oranının vuruk meyve oranına etkileri

Çalışmada kullanılan domates çeşitlerinde $T$. absoluta'nın yeşil aksamda oluşturduğu zarara ek olarak vuruk meyve oranına (\%) etkisini belirlemek amacıyla da çalışmalar gerçekleștirilmiştir. $\mathrm{Bu}$ amaçla deneme başlangıcında her parselden 3 bitki tesadüfi olarak seçilerek işaretlenmiş ve her hasat dönemi sırasında pazar değerini yitirmemiş mikroskop altında kontrol edilerek saptanan $T$. absoluta yumurta ve larva sayıları kaydedilmiştir. Kontrol edilen her parselde saptanan haftalık bulaşı $T$. absoluta yaprak sayısının alınan toplam örnek sayısına bölümü ile yüzde bulaşıklık oranları belirlenmiştir. Çalışmada çeșitlerin tamamında $T$. absoluta'ya karşı herhangi bir mücadele yapılmamıştır.

tüm meyveler toplanarak tartılmış ve kaydedilmiştir. Hasat edilen meyveler arasında "vuruk" olarak nitelenen $T$. absoluta zararı oluşmuş meyveler ise ayrıca tartılarak vuruk meyve miktarı belirlenmiş ve toplam meyve miktarına oranlanarak her bir çeşit için vuruk meyve oranı saptanmıştır. 


\section{İstatistiki Analiz}

Denemelerde kullanılan tüm domates çeşitlerinde oluşan $T$. absoluta yüzde zarar oranını belirlemek için her iki yılda da her uygulama için zarar görmüş ve görmemiş toplam bitki sayılarına Ki-Kare analizi yapılarak uygulamalar arasinda fark olup olmadığı belirlenmiştir. Uygulamalar arasında fark bulunması durumunda ise verilere ikili Ki-Kare analizi yapilarak hangi uygulamaların birbirlerinden farklı olduğu

\section{Sonuçlar ve Tartışma}

Farklı domates çeşitlerinin tarla koşullarında Tuta absoluta'ya etkileri

İkibin ondört y1l üretim sezonunda $T$. absoluta'nın Pembe, 5656, BT-236 ve BTTokat domates çeşitlerinde ergin öncesi toplam ortalama bulaşıklık oranları sırasıyla $\% 13.18, \quad 17.62, \quad 19.21$ ve 23.02 olarak saptanmıştır. Bu sonuçlara bağlı olarak BTTokat çeşidi, zararlı tarafından diğer çeşitlere ortaya çıkarılmış ve sonuçlar yüzde değer olarak sunulmuștur $(\mathrm{P}<0.05)$. Her çeșit için hasat sonrasinda elde edilen vuruk meyve tartım sonuçları arasındaki istatistiki olarak farkın belirlenmesi için verilere tek yönlü varyans analizi uygulanmıştır. Ortalamalar arasında istatistiki olarak fark olmas1 durumunda Duncan çoklu karşılaştırma testi kullanılmıştır $(\mathrm{P}<0.05)$. oranla daha çok tercih edilmiş; 5656 ve Pembe çeşitlerinden istatistiki olarak farklı grup içinde yer almıştır $\quad(\mathrm{Ki}-\mathrm{Kare}=23.03, \mathrm{df}=3$, $\mathrm{P}<0.001$ ) (Şekil 1). Çalışmada kullanılan domates çeşitleri arasında T. absoluta' ya karş1 en az duyarlı çeşit ise \%13.18 zarar oranı ile Pembe domates çeşidi olmuştur.

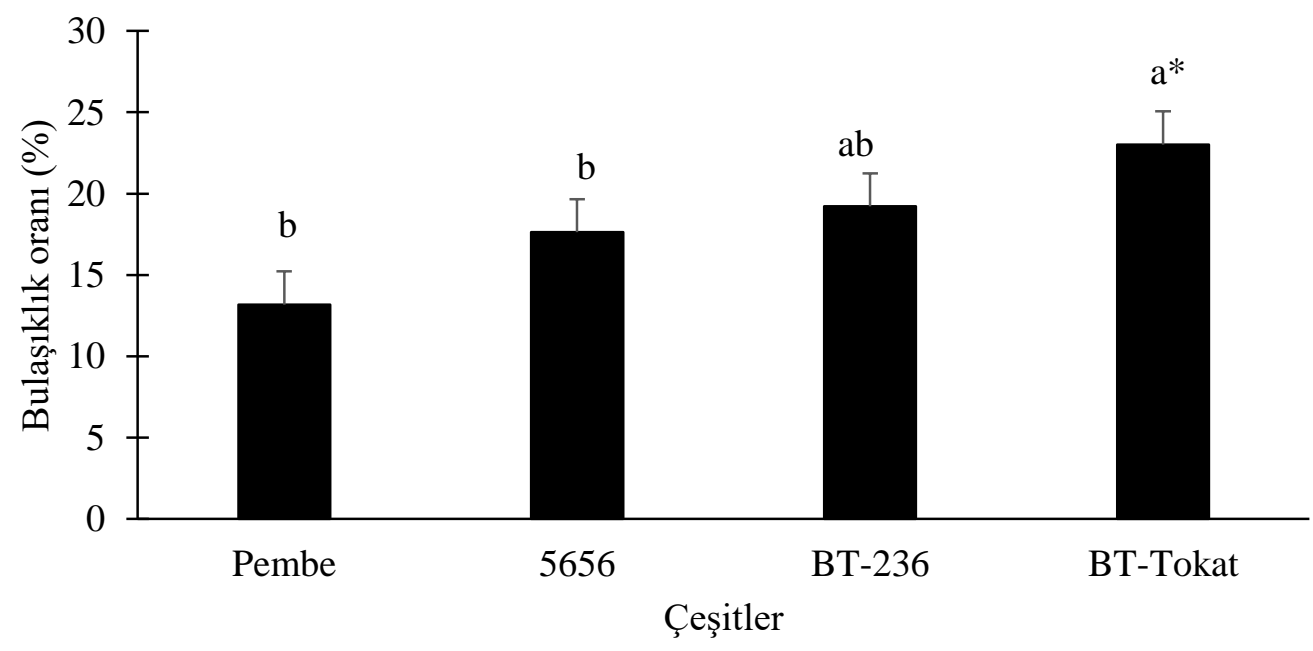

Şekil 1. Çamköy (Milas, Muğla)'de 2014 y1lı üretim sezonunda farklı domates çeşitlerinin üzerinde Tuta absoluta'nın yumurta ve larva bulaşıklık oranlarına etkisi. *Aynı harfi içeren değerler arasındaki fark istatistiki olarak önemsizdir (Ki-Kare, $\mathrm{P}<0.05),(\mathrm{Ort} . \pm \mathrm{SH})$

İkibin ondört y1l üretim sezonunda $T$. absoluta'nın Pembe, 5656, BT-236 ve BTTokat çeşitlerinde en yüksek bulaşıklık oranları sirasiyla $\% 48.89,68.89,77.78$ ve 80.00 olarak saptanmıştır. Söz konusu bulaşıklık oranlarının izlenme tarihleri Pembe 


\section{Bazı Domates Çeşitlerinin Milas (Muğla) Tarla Koşullarında Tuta absoluta'nın Ergin Öncesi Popülasyon Yoğunluğuna Etkileri}

ve BT-Tokat çeşitlerinde 28 Temmuz, BTTokat ve 5656 çeşitlerinde ise 4 Ağustos olarak gerçekleşmiştir.

İkibin onbeş y1lı üretim sezonunda $T$. absoluta'nın Pembe, BT-236, 5656 ve BTTokat çeşitlerinde ergin öncesi toplam ortalama bulaşıklık oranları sırasıyla \% 4.28 , $4.28,6.39$ ve 7.39 olarak gerçekleşmiştir. 2014 yılına benzer şekilde en yüksek bulaşıklık oranı yine BT-Tokat çeşidinde saptanırken en az bulaşıklık oranı da yine Pembe domates çeşidinde izlenmiş ve her iki çeşit arasındaki fark istatistiki olarak önemli bulunmuştur $(\mathrm{Ki}-\mathrm{Kare}=24.36$; df=3; $\mathrm{P}<0.001)$ (Şekil 2).
İkibin onbeş y1lı üretim sezonunda $T$. absoluta'nın Pembe, 5656, BT-236 ve BTTokat çeşitlerinde en yüksek bulaşıklık oranları sirasiyla $\% 6.67,12.67,10.67$ ve 16.67 olmuştur. Söz konusu bulaşıklık oranlarının görülme tarihleri BT-236 ve BT-Tokat çeşitlerinde 17 Ağustos, Pembe ve 5656 çeşitleri için ise sırasıyla 20 Temmuz ve 27 Temmuz olarak gerçekleşmiştir. $\mathrm{Bu}$ sonuçlarla her iki üretim sezonunda da $T$. absoluta' ya karş1 en az duyarlı domates çeşidi yerel çeşit Pembe olurken en duyarlı çeşit ise BT-Tokat olarak belirlenmiştir.

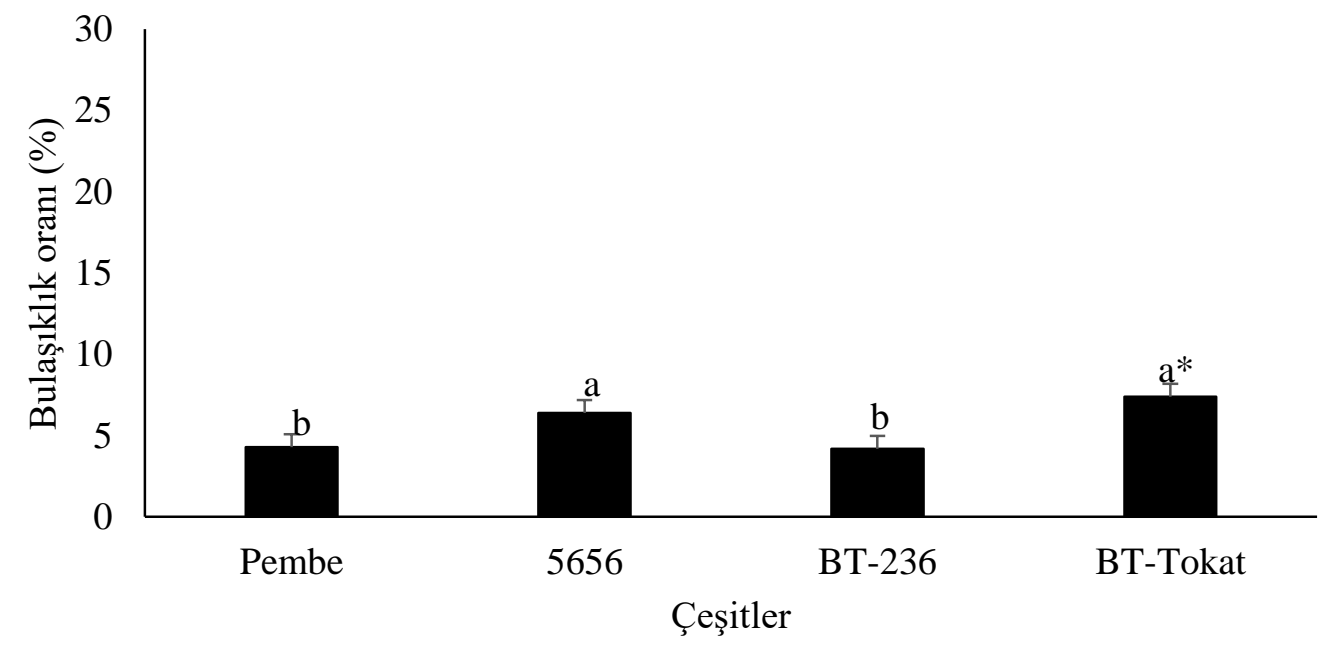

Şekil 2. Çamköy (Milas, Muğla)'de 2015 yılı üretim sezonunda farklı domates çeşitlerinin üzerinde Tuta absoluta'nın yumurta ve larva bulaşıklık oranları. *Aynı harfi içeren ortalama değerler arasındaki fark istatistiki olarak önemsizdir (Ki-Kare, $\mathrm{P}<0.05),(\mathrm{Ort} . \pm \mathrm{SH})$

\section{Farklı domates çeşitlerinde vuruk meyve oranları}

Tuta absoluta'nın meyvede oluşturduğu zarara ve vuruk meyve oranına farklı domates çeşit etkisi incelendiğinde; en düşük vuruk meyve oranı her iki üretim sezonunda da; 2014 ve 2015 yılları için sırasıyla \%14.52 ve

5.30 olarak üzere yerel çeşit Pembe'de görülmüştür. En yüksek vuruk oranları ise; 2014 ve 2015 üretim sezonu için sirasiyla $\% 31.99$ ile BT-236 ve \%16.83 ile BT-Tokat çeşidinde görülmüş̧ür. 


\section{Bazı Domates Çeşitlerinin Milas (Muğla) Tarla Koşullarında Tuta absoluta'nın Ergin Öncesi Popülasyon Yoğunluğuna Etkileri}

İkibin ondört y1lı üretim sezonunda uygulamalardaki vuruk meyve miktarları Pembe, BT-Tokat, 5656 ve BT-236 domates çeşitleri için sırasıyla $0.53,1.06,1.26$ ve 1.59 $\mathrm{kg} /$ bitki olmuştur. Yapılan istatistiki analiz sonucunda uygulamalar arasındaki fark önemli bulunmuş ve sadece Pembe çeşidinde görülen vuruk meyve miktarı, BT-Tokat dışında kalan diğer çeşitlerde görülen vuruk meyve miktarından istatistiki açıdan farklı düzeyde ve düşük olarak gerçekleşmiştir $(\mathrm{F}=$ 4.38; $\mathrm{df}=3 ; \mathrm{P}=0.011)$ (Çizelge 2).

Çizelge 2. Çamköy (Milas, Muğla)'de 2014 yılı üretim sezonunda farklı domates çeşitlerinin ortalama ürün ve vuruk meyve oranına etkisi $(\mathrm{kg} \pm \mathrm{SH})^{*}$

\begin{tabular}{|c|c|c|c|}
\hline Çeşit & $\begin{array}{c}\text { Ortalama Ürün } \\
\text { (kg/bitki) }\end{array}$ & $\begin{array}{c}\text { Ortalama Vuruk } \\
\text { Meyve (kg/bitki) }\end{array}$ & $\begin{array}{c}\text { Ortalama Vuruk } \\
\text { Meyve Oranı (\%) }\end{array}$ \\
\hline BT-236 & 4.97 & $1.59 \pm 0.22$ a & 31.99 \\
\hline BT-Tokat & 4.68 & $1.06 \pm 0.18$ ab & 22.65 \\
\hline 5656 & 4.96 & $1.26 \pm 0.25$ a & 25.40 \\
\hline Pembe & 3.65 & $0.53 \pm 0.16 \quad$ b & 14.52 \\
\hline
\end{tabular}

(*)Aynı harfi içeren ortalama değerler arasındaki fark istatistiki olarak önemsizdir (Duncan; $\mathrm{P}<0.05$ ).

İkibin onbeş y1lı üretim sezonunda Pembe, 5656, BT-236 ve BT-Tokat çeşitlerinde vuruk meyve miktarları sirasiyla $0.08,0.21,0.31$ ve $0.34 \mathrm{~kg} /$ bitki olmuştur. Saptanan vuruk meyve miktarları arasındaki fark istatistiki olarak önemli bulunmuş, 5656 ve Pembe çeşitlerinde görülen vuruk meyve

miktarları diğer 2 çeşitte görülen vuruk meyve miktarlarına oranla istatistiki olarak farkl1 düzeyde düşük gerçekleşmiştir $(\mathrm{F}=9.11 ; \mathrm{df}=$ 3; $\mathrm{P}<0.001$ ) (Çizelge 3).

Çizelge 3. Çamköy (Milas, Muğla)'de 2015 y1lı üretim sezonunda farklı domates çeşitlerinin ortalama ürün ve vuruk meyve oranına etkisi $(\mathrm{kg} \pm \mathrm{SH})^{*}$

\begin{tabular}{|c|c|c|c|}
\hline Çeşit & $\begin{array}{c}\text { Ortalama Ürün } \\
\text { (kg/bitki) }\end{array}$ & $\begin{array}{c}\text { Ortalama Vuruk } \\
\text { Meyve (kg/bitki) }\end{array}$ & $\begin{array}{c}\text { Ortalama Vuruk } \\
\text { Meyve Oranı (\%) }\end{array}$ \\
\hline BT-236 & 1.86 & $0.31 \pm 0.05$ a & 16.67 \\
\hline BT-Tokat & 2.02 & $0.34 \pm 0.05$ a & 16.83 \\
\hline 5656 & 2.05 & $0.21 \pm 0.01 \quad \mathrm{~b}$ & 10.24 \\
\hline Pembe & 1.51 & $0.08 \pm 0.03 \quad \mathrm{c}$ & 5.30 \\
\hline
\end{tabular}

(*)Aynı harfi içeren ortalama değerler arasındaki fark istatistiki olarak önemsizdir (Duncan; $\mathrm{P}<0.05$ ).

Çalışmanın yapıldığ 1 her iki üretim sezonunda da $T$. absoluta bulaşıklık oranının en düşük olduğu çeşit yerel çeşit Pembe olmuştur. Bulaşıklık oranı 2014 ve 2015 üretim yılları için sırasıyla \%13.18 ve 4.28 olarak saptanmıştır. Herbivor böceklerin konukçularında zarar meydana getirmesinde bitki dayanıklılığı, konukçunun besin değeri, bitkinin morfolojik yapısı (bitki dokusunun kalınlığı-inceliği, bitki yüzeyinin tüylülüğü) ve bitkinin kimyasal yapisında bulunan metabolitler önemli rol oynamaktadır. Bunun yanı sıra besin kaynağının kalitesi ve içerdiği bileşikler, fitofag böceklerin gelişme süresi, bıraktığı yumurta sayısı ve ölüm oranı gibi yaşamsal parametreleri üzerinde etkili olmaktadır (Rostami ve ark., 2017). Çalışmada kullanılan domates çeşitleri morfolojik olarak karşılaştırıldığında aralarında belirgin bir fark 


\section{Bazı Domates Çeşitlerinin Milas (Muğla) Tarla Koşullarında Tuta absoluta'nın Ergin Öncesi Popülasyon Yoğunluğuna Etkileri}

bulunmadığ 1 gözlenmiştir. Çeşitler üzerinde trikom yoğunluğu açısından ayrı bir çalışma yapılmamakla birlikte yerel çeşit Pembe'nin görece olarak bu özellik açısından diğer çeşitlere göre daha zengin olduğu dikkat çekmiştir. Domates bitkisinin sahip olduğu trikomlar ve bunlarda yer alan keselerin zehirlilik özellikleri nedeni ile herbivorların başarılı bir şekilde beslenme ve üremelerine engel oldukları bilinmektedir (Sohrabi ve ark., 2016). Sridhar ve ark. (2019), yabani domates çeşitlerinde görülen Tip IV trikomun, T. absoluta'da görece olarak daha fazla larva ölümü, uzun larva gelişim süresi ve düşük oranda pupadan ergin çıkışına neden olduğunu bildirmişlerdir. Yabani domates çeşitlerinde görülen Tip I ve VII trikomların zararlı üzerinde olumsuz etki meydana getirdiği saptanmış olup; Tip IV trikoma sahip çeşitlerde yüksek oranda flavonoid ve fenollerin bulunduğu belirlenmiştir.

Yabani domateslerde özellikle bitkinin üst kısımlarındaki genç yapraklarda bol miktarda bulunan trikomlara ek olarak 2-tridecanone, acyl sugar gibi allelokimyasalların böceklerin yumurta bırakmasını ve genç dönemlerinin beslenmesini engelleyici etki göstererek bitkide zararlılara karşı dayanıklılık sağladığı belirlenmiştir (Neiva ve ark., 2013; Dias ve ark., 2016). Yumurtadan yeni çıkan T. absoluta larvalarının, 2-tridecanone içeriği yüksek olan yapraklarda beslendiğinde 1-2 gün içerisinde öldükleri saptanmıştır (Ryan, 2002). Bunun yanı sira ikincil metabolit methyl ketonun da $T$. absoluta'ya karşı bitkide dayanıklılık oluşumunu teşvik ettiği bildirilmiştir (Vitta ve ark., 2016).

Çalışmanın yapıldığ da en düşük vuruk meyve oranı (\%) 2014 ve 2015 y1lları için sırasıyla \%14.52 ve \%5.30 ile yerel çeşit Pembe'de izlenmiştir. T. absoluta'nın

\section{Teșekkür}

Bu çalışmayı FDK-2014-3036 proje numarası ile destekleyen Çukurova Üniversitesi Araştırma Projeleri Birimi'ne teşekkür ederiz.

\section{Kaynaklar}

Abak, K., 2016. Türkiye'de Domatesin Dünü, Bugünü ve Yarını. www.turktob.org.tr
Pembe domates çeşidi meyvelerini diğer domates çeşitlerinin meyvelerine göre daha az tercih etmesinin nedeni; zararlının konukçu bitkiyi sahip olduğu ve yukarda açıklanan özellikler doğrultusunda konukçu olarak daha az tercih etmesi ve buna bağlı olarak meyvede daha az görülmesine bağlanmıştır. Besin kaynağının kalitesi ve içerdiği bileşikler, herbivorların yaşam parametreleri (gelişme süresi, ölüm oranı, yumurta sayısı) üzerinde etkilidir (Rostami ve ark., 2017). Bu bağlamda; meyvenin kimyasal yapısının T. absoluta için vuruk meyve oranında etkili olduğu farklı araştırmacılar tarafından bildirilmiştir. Silva ve ark. (2015), acyl şeker miktarı yüksek olan domates çeşitlerinin $T$. absoluta'ya karşı daha dayanıklı olduğunu belirtmişlerdir. Acyl sugar'a ek olarak sakkarozun ise, T. absoluta'yı diğer şeker çeşitlerine oranla daha çok cezbettiği saptanmıştır (Beck., 1956; Salama ve ark., 2015 'ten).

Çalışma sonunda elde edilen sonuçlara dikkate alındığında domates üretiminde tercih edilecek çeşidin zararlıya karşı dayanıklı olup-olmadığ göz önünde bulundurulması oluşacak zararın düşürülmesinde önemli olduğu görülmüştür. Yapılan çalışmalardan elde edilen sonuçlara bağlı olarak yerel çeşit Pembe'nin diğer çeşitlere göre T. absoluta'ya daha dayanıklı olduğunun ortaya çıkarılmasında trikom özellikleriyle birlikte morfolojik ve biyokimyasal özelliklerinin ortaya çıkarılması faydalı olacaktır. Meyve şeker oranının T. absoluta'nın meyvede beslenme tercihi açısından önemli olması nedeni ile Pembe domates çeşidinde tirichom tipi ve yoğunluğu ile birlikte meyve şeker tipi ve oranlarının da ayrıntılı olarak çalışılması, T. absoluta'ya karşı konukçu bitkinin dayanıklılık durumu ve nedenlerinin detaylı olarak belirlenmesine yardımcı olacaktır.

\section{/dergi/makaleler/dergi17/TTOB_Dergi1 7_WEB-8_13.pdf. Erişim tarihi: 11.01 .2018}

Anonim, 2011. Tarım ve Köyişleri Bakanlığı, Koruma ve Kontrol Genel Müdürlüğü (Web Sayfası: www.tarim.gov.tr), Domates Hastalık ve Zararlıları ile Mücadele (Çiftçi Eğitim Serisi: 7) (5-6). 


\section{Bazı Domates Çeşitlerinin Milas (Muğla) Tarla Koşullarında Tuta absoluta'nın Ergin Öncesi Popülasyon Yoğunluğuna Etkileri}

Aslan, M.M., Gençoğlan, S., Aygel, G., Ücük, C., 2017. Kahramanmaraș İlinde Sera Koșullarında Tuta absoluta (Meyrick) (Lepidoptera: Gelechiidae) (Domates Güvesi)'nin Popülasyon Yoğunluğu. KSÜ Doğa Bilimleri Dergisi, 20 (4), 339343.

Dias, D.M., Resende, J.T., Marodin, J.C., Mantos, R., Lustosa, I.F., Resende, N.C., 2016. Acyl sugars and whitefly (Bemisia tabaci) resistance in segregating populations of tomato genitypes. Genetics and Molecular Research, 2: 7-15.

Dos Santos, A.C., Bueno, R.C.O.F., Vieiria S.S., Bueno, A.D.F., 2011. Efficacy of insecticides on Tuta abssoluta (Meyrick) and other pests in pole tomato. Bioassay: 6:4, 1-6.

Ecole, C.C., M.C. Picanceo, R.N.C. Guedes and S. H. Brommonsschenkel, 2001. Effect of cropping season and possible compounds involved in the resistance of Lycopersicon hirsutum f. typicum to Tuta absoluta (Meyrick) (Lep., Gelechiidae) Journal of Applied Entomology, 125, 193-200.

EPPO, 2009. Pests and diseases. In European and Mediterranean Plant Protection Organisation Reporting Service. http://archives.eppo.org/EPPOReporting/ 2009/Rse-0908.pdf (Erişim tarihi: 11 Mart 2015).

Karut, K., Kazak, C., Döker, İ., Ulusoy, M.R., 2011. Mersin ili domates seralarında Domates yaprak galeri güvesi Tuta absoluta (Meyrick, 1917) (Lepidoptera: Gelechiidae)'nın yaygınlığı ve zarar durumu. Türkiye Entomoloji Dergisi, 35 (2): 339-447.

Kasap, İ., Gözel, U., Özpınar, A., 2011. Yeni bir zararl1; domates güvesi Tuta absoluta (Meyrick, 1917) (Lepidoptera: Gelechiidae). Çanakkale Tarım Sempozyumu (Dünü, Bugünü, Geleceği) Bildirileri, s. 284.

K1lıç, T., 2010. First record of Tuta absoluta in Turkey (Meyrick, 1917). Phytoparasitica, 38 (3): 243-244.

Leite, G.L.D., Picanço, M., Guedes, R. N. C., Zanuncio, J.C., 2001. Role of plant age in the resistance of Lycopersicon hirsutum $\mathrm{f}$. glabratum to the tomato leafminer Tuta absoluta (Lepidoptera: Gelechiidae). Scientia Horticulturae 89: 103-113.

Mahmoud, Y.A., Salem, H.A., Shalaby, E.M., Abdel-Rezak, A.S., Ebadah, I.M.A., 2014. Effect of certain low toxicity insecticides against Tomato leaf miner, Tuta absoluta (Lepidoptera: Gelechiidae) with reference to their residues in harvested tomato fruits. International Journal of Agricultural Research, 9 (4): 210-218.

Mamay, M., Yanık, E., 2012. Şanlıurfa'da domates alanlarında Domates güvesi [Tuta absoluta (Meyrick) (Lepidoptera: Gelechiidae)]'nin ergin popülasyon gelișimi. Türkiye Entomoloji Bülteni, 2012, 2 (3): 189-198.

Manavoğlu, M., Kayahan, A., Karaca, İ., 2019. Tuta absoluta (Meyrick) (Lepidoptera: Gelechiidae) ile Mücadelede Topraktan Uygulanan Bazı Pestisitlerin Etkisi. Süleyman Demirel Üniversitesi Fen Bilimleri Enstitüsü Dergisi, 23 (1): 133139.

Neiva, I.P., Andrade, Jr.V.C., Maluf, W.R., Oliveira, C.M., Manuel, G.M., 2013. Role of allelocehmicals and trichome density in the resistance of tomato to whitefly. Cinênc. Agrotec. 37 (1): 61-67.

Oliveira, C. M., Andrade J, V. C., Maluf, W. R., Neiva, I. P., Maciel, G. M., 2012. Resistance of tomato strains to the moth Tuta absoluta imparted by allelochemicals and trichome density. Ciência e Agrotecnologia, 36 (1), 45-52.

Rostami, E., Madadi, H., Abbasipour, H., Alahyari, H. and Cuthbertson, A.G.S., 2017. Life Table parameters of the tomato leaf miner Tuta absoluta (Lepidoptera: Gelechiiade) on different tomato cultivars. Journal of Applied Entomology, $141,88-96$.

Ryan, M.F., 2002. Insect Chemoreception Fundamental and Applied, 236. p. Oliveira F. A., Silva, D. J. H. and Leite, G.L.D., 2009. Resistance of 57 greenhouse-grown accessions of Lycopersicon esculentum and three cultivars to Tuta absoluta (Meyrick) 


\section{Bazı Domates Çeşitlerinin Milas (Muğla) Tarla Koşullarında Tuta absoluta'nın Ergin Öncesi Popülasyon Yoğunluğuna Etkileri}

(Lepidoptera: Gelechiidae). Scientia Horticulturae 119: 182-187.

Salama, H.S.A.E., Abdel-Khalek, I., Fouda, I.M., Ebadah, I., Shehota, I., 2015. Some Ecological and Behavioral Aspects of the Tomato Leaf Miner Tuta absoluta (Meyrick) (Lepidoptera: Gelechiidae). Ecologia Balkanica, 7 (2): 35-44.

Silva, D.B., Bueno, V.H.P., Jr. Lins, C.J., Van Lenteren, J.C., 2015. Life history dataand population growth of Tuta absoluta at constant and alternating temperatures on two tomato lines. Bulletin of Insectology 68 (2): 223-232.

Silva, D.B., Bueno, V.H.P., Jr. Lins, C.J., Van Lenteren, J.C., 2015. Life history dataand population growth of Tuta absoluta at constant and alternating temperatures on two tomato lines. Bulletin of Insectology 68 (2): 223-232.

Sohrabi, F., Nooryazdan, H., Gharati, B. and Saeidi, Z., 2016. Evaluation of ten tomato cultivars for resistance against tomato leaf miner, Tuta absoluta (Meyrick) (Lepidoptera: Gelechiidae) under field infestation conditions. Entomologia Generalis, 36 (2): 163-175.

Sridhar, V., Sadashiva, A.T., Rao, V.K., Swathi, P. AND Gadad, H.S., 2019. Trichome and biochemical basis of resistance against Tuta absoluta in tomato genotypes. Plant Genetic Resources, 1-5. doi: $10.1017 / \mathrm{S} 147926211800062 \mathrm{X}$.

Urbaneja, A., Vercher, R., Navarro, V., Porcuna, J. L. \& García-Marí, F., 2007. La polilla del tomate, Tuta absoluta. PhytomaEspaña, 194: 16-24.

Vitta, N., Estay, P. ve Chorbadjian, R. A., 2016. Characterization of resistance expression in genotypes of Solanum Section Lycopersicon against Tuta absoluta (Lepidoptera: Gelechiidae). Ciencia e Investigación Agraria 43(3):366-373. 
Bazı Domates Çeşitlerinin Milas (Muğla) Tarla Koşullarında Tuta absoluta'nın Ergin Öncesi Popülasyon Yoğunluğuna Etkileri

Aslan, M.M., Gençoğlan, S., Aygel, G., Ücük, C., 2017. Kahramanmaraş İlinde Sera Koşullarında Tuta absoluta (Meyrick) (Lepidoptera: Gelechiidae) (Domates Güvesi)'nin Popülasyon Yoğunluğu. KSÜ Doğa Bilimleri Dergisi, 20 (4), 339-343. 